Discussion Paper No. 18-051

Path Dependencies versus Efficiencies in Regulation: Evidence from "Old" and "New" Broadband Markets in the EU

Wolfgang Briglauer, Enrico Maria Camarda, and Ingo Vogelsang

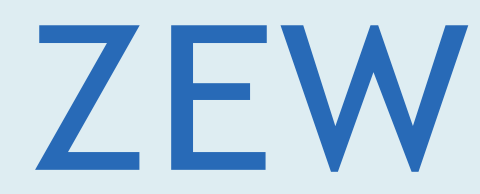

Zentrum für Europäische Wirtschaftsforschung $\mathrm{GmbH}$ Centre for European Economic Research 
Discussion Paper No. 18-051

\title{
Path Dependencies versus Efficiencies in Regulation: Evidence from "Old" and "New" Broadband Markets in the EU
}

\author{
Wolfgang Briglauer, Enrico Maria Camarda, \\ and Ingo Vogelsang
}

Download this ZEW Discussion Paper from our ftp server:

http://ftp.zew.de/pub/zew-docs/dp/dp18051.pdf

Die Discussion Papers dienen einer möglichst schnellen Verbreitung von neueren Forschungsarbeiten des ZEW. Die Beiträge liegen in alleiniger Verantwortung der Autoren und stellen nicht notwendigerweise die Meinung des ZEW dar.

Discussion Papers are intended to make results of ZEW research promptly available to other economists in order to encourage discussion and suggestions for revisions. The authors are solely responsible for the contents which do not necessarily represent the opinion of the ZEW. 


\section{Path Dependencies versus Efficiencies in Regulation: Evidence from "Old" and "New" Broadband Markets in the EU}

Briglauer, Wolfgang*, Camarda, Enrico Maria**, Vogelsang, Ingo***

November, 2018

* Wolfgang Briglauer, ZEW Mannheim, e-mail: wolfgang.briglauer@zew.de, phone: +49 (0) 621 1235-279. P.O. Box 103443, 68034 Mannheim, Germany.

** Enrico Maria Camarda, Economics Department, KU Leuven, email: enricomaria.camarda@kuleuven.be, 3000 Leuven, Belgium.

*** (corresponding author) Ingo Vogelsang, Economics Department, Boston University, College of Arts and Sciences, e-mail: vogelsan@bu.edu, Boston, USA.

\section{Keywords}

Broadband markets; "old" and "new" networks; EU regulatory framework; normative theory; positive theory; path dependence; bureaucracy; EU panel data

\section{Acknowledgements}

The authors would like to thank Marc Bourreau, Klaus Gugler, Mattia Nardotto and Frank Verboven for highly valuable comments. Furthermore, the authors are grateful for comments and suggestions of the participants at the scientific seminar at the EUI in Florence in March 2017, the 28 ${ }^{\text {th }}$ ITS conference in Passau in August 2017 and at the ZEW/ICT seminar in Mannheim in November 2018. Finally, financial support by the State Government of Baden-Württemberg, Germany, through the research program "Strengthening Efficiency and Competitiveness in the European Knowledge Economies" (SEEK) is gratefully acknowledged. 


\section{Abstract}

This paper examines the determinants of sector-specific regulation imposed on broadband markets related both to efficiency objectives of regulators and to those of narrowly defined interest groups. We test hypotheses derived from the normative and positive theoretical literature employing recent panel data on 27 European Union member states taking into account endogeneity of the underlying regulation and market structure variables. Our empirical specification employs three different estimators based on instrumental variables in order to identify causal effects. We find evidence supporting both regulators pursuing normative objectives and inefficiencies related to regulatory path dependence, bureaucracy goals and an inadequate consideration of competition from mobile broadband networks. Our results call for adjustments in the institutional design of the decision making process under the current European Union regulatory framework. 


\section{Introduction}

In a time of increasing digitalization, operators of "old" broadband networks are facing a challenging increase in demand for bandwidth and for meeting real time criteria. "New" broadband networks based on optical fiber technology (so called "Next Generation Network(s)" - NGN) enable a massive increase in bandwidth capacity and the adoption of entirely new services on the demand side. One of the main policy goals is thus to incentivize investment in new high-speed broadband infrastructure in view of its economic importance related to increased productivity and other positive externalities in major industry sectors (Bertschek et al., 2016).

One of the most important aspects of the European Union (EU) regulatory framework for electronic communications is the regulation of broadband access infrastructures which form the basis for the entire digital economy. Since the very beginning of the liberalisation process in 1997/1998, broadband markets have been subjected to a broad system of wholesale access obligations under the EU regulatory framework for electronic communications markets (European Commission, 2002a). Access obligations have been imposed asymmetrically on the legacy infrastructure of market dominant operators, so-called "incumbents". ${ }^{1}$ "Wholesale-access-based" operators can rent the incumbent's legacy access infrastructure typically based on cost-oriented wholesale prices for various access products which differ in scope of technological product differentiation. Wholesale-

\footnotetext{
${ }^{1}$ The term "incumbent" refers to former - mostly state-owned - telecommunications monopolists of "legacy" copper-wire infrastructure that existed prior to market liberalization. Cable-TV coaxialwire networks also represent "old" broadband networks. However, only copper-wire based legacy networks have been subjected to sector-specific access regulations under the EU framework.
} 
based access competition hinges directly upon a set of pre-defined wholesale access regulations. Provided access obligations are effectively implemented by the national regulatory authorities (regulators) alternative operators can offer competitive retail broadband services without getting engaged in time-consuming, costly, and risky roll-out of own access network infrastructure. In the early stages of market liberalization wholesale-access-based competition massively increased price competition and thus yielded an immediate static welfare gain. With respect to emerging NGN infrastructure, the EU regulatory framework has during the time of our observation foreseen a similar, although not quite as strict mandatory access pricing regime which is rather comprehensive and intense in comparison to the US or to fiber leading East-Asian countries (Vogelsang, 2013; 2015). The European Commission's (EC's) approach to the regulation of NGN can thus be seen as an extension of the EU regulatory framework originally created for the old broadband legacy networks. In particular, the regulatory framework has been supplemented by NGN related recommendations (European Commission, 2010; 2013; 2016a) which form the relevant regulatory framework for NGN infrastructure. It appears that two decades of EU broadband regulations created a strong element of path dependence (Cave and Feasey, 2017).

However, in the academic literature there is much more controversy whether NGN access regulation is still required. From a pure efficiency perspective ${ }^{2}$ regulation

\footnotetext{
${ }^{2}$ In contrast, the European regulatory framework explicitly emphasizes a consumer perspective (European Commission, 2002a, Art 8 (2) lit a: „ensuring that users, including disabled users, derive maximum benefit in terms of choice, price, and quality"). Regarding network operators only investment incentives are mentioned but not profits.
} 
would be justified only in view of persistent monopolistic market structures that constitute an "essential facility" which cannot be economically replicated by other operators. The underlying essential facilities doctrine has its origins in US law (Arreda, 1989; Lipsky and Sidak, 1999) and basically applies to markets that exhibit natural monopoly characteristics. ${ }^{3}$ According to an EU interpretation of the essential facilities doctrine, legacy network operators would enjoy positions of dominance which, in the absence of mandatory access obligations at the wholesale level, would give rise to static and dynamic inefficiencies. ${ }^{4}$ Only if this case prevailed would a set of access regulations imposed on emerging NGN infrastructure be economically justified. In contrast, however, under the comprehensive sector-specific regulatory framework as issued by the EC in its directives, guidelines and recommendations and as imposed by most national regulators on old and new broadband markets, new regulations might also be seen as the result of path dependence and institutional dimensions. Against this backdrop, we want to address the following research questions:

\footnotetext{
${ }^{3}$ The doctrine goes back to the Terminal Railroads case in 1912. The specific conditions of an essential facility were laid out in the case $\mathrm{MCl}$ Communications Co v. AT\&T (708 F.2d 1081) in 1982.

${ }^{4}$ Under EC law the essential facilities doctrine has been based on Art 82 of the EC Treaty (Art 102 TFEU) which prohibits abuse of market dominance. Later on the doctrine has also become an integral part of the EU regulatory framework (European Commission,1998). The implementation of the EU 2002 regulatory framework (European Commission, 2002a,b), however, led to a direct reliance on the concept of market dominance as applied under Art 82 (102), which entailed a more indirect linkage to the essential facilities doctrine; indeed, sector-specific regulations have opened up much more than essential facilities since the implementation of the $2002 \mathrm{EU}$ framework.
} 
$R Q$ 1: Does regulation of new broadband infrastructure depend solely on market features related to dominance in new broadband markets (as it is supposed to be according to sector-specific telecommunications law and economic efficiency)?

$R Q$ 2: Does regulation of new broadband infrastructure also depend on old broadband regulations (path dependence) and other institutional factors (such as NGN regulation in other EU member states, EU harmonization)?

Answering these questions yields some immediate and highly important policy implications. In particular, if our results would point to a strong element of path dependence, then this would fundamentally call into question the regulatory framework on efficiency grounds.

A further complexity arises from the fact that wholesale broadband access is not exclusively based on regulation that is asymmetrically imposed on dominant operators (European Commission, 2002b, Art 12 and 13), but rests more and more on different forms of symmetric regulation (European Commission, 2010, recitals $12,15,19,27$, Art 13 and 16) which are imposed (symmetrically) on all network operators irrespective of positions of dominance. Symmetric regulations, such as the provisions on mutual duct access sharing, are targeted to share investment risks and to decrease total deployment costs. In view of high investments required for a broad-scale NGN roll-out, symmetric regulations have increasingly gained importance in recent years. While such symmetric regulations can be justified from an efficiency and/or consumer welfare perspective, the question is why firms do not voluntarily engage in the same activities. One reason could be that such activities interfere with competition laws and therefore may require ex ante 
authorization. In terms of the two research questions above symmetric regulations fall into neither category. They do not depend on market features related to dominance, and they are largely NGN-specific and therefore not path dependent.

Our empirical investigation is the first that employs data on old and new access regulations in a comprehensive EU27 panel for the years from 2003 to 2015. Our econometric specification accommodates i) the categorical nature of dependent variables measuring NGN regulation and ii) potential endogeneity utilizing three alternative estimators (control function model, linear probability model and Arellano-Bond model) which all rest on instrumental variables panel estimation techniques. In view of both research questions we find supportive evidence on related hypotheses derived from the normative and positive theoretical literature.

Section 2 first reviews the related literature and Section 3 outlines testable hypotheses based on our reading of this literature. Section 4 presents the empirical baseline specification and our identification strategy. Section 5 describes our panel data set. Section 6 discusses the main empirical results. Section 7 summarizes and compiles relevant policy recommendations. 


\section{Literature}

Migration from copper or cable legacy networks to fibre-based networks takes place gradually, suggesting that, during a transition phase, two different sets of access regulations will exist in parallel and both, old and new regulations will have an impact on NGN market outcomes. Whereas new access regulations exert a direct impact on NGN markets, old regulations exert more indirect effects as shown theoretically in Bourreau et al. (2012). They might also shape new regulations.

As there is no empirical literature on the determinants of NGN regulation available so far, we first refer to the NGN related literature on the linkage between old legacy regulation and NGN investment as reviewed in Briglauer et al. (2015). Whereas the theoretical literature highlights several opposing effects at the firm level, the few contributions from the empirical literature available so far point to a negative relationship. This corroborates the results of the literature that studies old broadband markets as surveyed in Cambini and Jiang (2009), which finds similar albeit less-pronounced empirical evidence. Indeed, the underlying differences between the economics of the old and the new broadband infrastructures are likely to aggravate the negative impact of access regulation on investment in the case of NGN. The main argument here is that the investment in NGN is more likely to suffer from the hold-up problem, because a large part of the legacy networks existed prior to the implementation of access regulation, whereas the fiber-optic elements of the access network need to be built anew. New investments might thus be subject to ex post expropriation by regulators in terms of strict access regulations. Anticipating this, infrastructure operators would not invest. This problem might be mitigated, if regulators can and do commit ex ante not to 
regulate too strictly. Expectations also play a role if old regulations can be seen as a proxy variable for future NGN regulations as operators will form expectations that are shaped on the basis of the existing infrastructure regulation. In the particular case of NGN deployment, potential investors would as a result of regulatory path dependence expect stricter future access regulations of NGN infrastructure, the stricter the existing old broadband infrastructure is regulated.

The theoretical literature relevant to our research questions can be divided into the normative and the positive literature, the former of which has evolved around the question of optimal wholesale access regulation (or the lack thereof) for legacy networks and NGN. Most prominent here features Bourreau et al. (2012), which distinguishes opposing effects for affecting NGN investments at the firm level so that the optimum will represent a compromise.

Not addressed by Bourreau et al. (2012) is the case of competitive areas, where both an entrant and the incumbent invest in NGN infrastructure. This case is taken up by Inderst and Peitz (2012a), who find that this can lead to a prisoners' dilemma, where both firms invest but would be better off not investing. Based on Inderst and Peitz (2012a;b), Vogelsang (2016) comes to the conclusion that NGN wholesale access should not be regulated if NGN investment is the objective. The main mechanism here is a Schumpeter effect, because not regulating the new infrastructure increases the appropriability of the investment rewards. Briglauer et al. (2018) study how the coexistence of access regulations for legacy (copper) and fiber networks shapes the incentives to invest in NGN infrastructures allowing for alternative firms with proprietary legacy network (cable operators) and the presence of asymmetric regulation on access to the incumbent's fiber network. Regarding the incumbent, their results show that access regulation imposed on 
fiber networks negatively affects incumbent's investment decision while the cable operators' decision to invest in fiber is not affected when they dominate NGN deployment.

In contrast to the normative theoretical literature, there seems to exist no positive theoretical literature directly to our research questions. We therefore allude to more general contributions that we then try to apply to the current context.

Path dependence of regulation of a NGN can have several reasons, which can be linked to i) established interest groups and ii) sunk past investment. These two types of reasons can themselves be linked to each other. There is a large literature on the effects of interest groups on regulation, going back mainly to Stigler (1971), Peltzman (1976) and Becker (1983). The main insights from this so-called "economic theory of regulation" are that winning interest groups tend to be small and tend to have a very strong interest in the particular type of regulation (Stigler, 1971). For instance, owners of sunk infrastructure would form a strong interest group because of the danger of regulatory expropriation. Furthermore, there tends to be more than one winning group, meaning that regulation will try to pacify groups to reduce their potential opposition to a policy (Peltzman, 1976). In an interest group context efficient regulation could result, if the increased surplus from such regulation can be used to pacify losing interest groups (Becker, 1983).

Before the advent of liberalization and competition in telecommunications the main relevant interest groups were the regulated firms represented by their shareholders and employees (plus suppliers depending on these firms) and the end-users (which might have divergent interest among themselves). Now, after competition has arrived there are two new interest groups, non-dominant (i.e. 
unregulated) infrastructure-based competitors, who do not have to supply wholesale access, and wholesale-access-based competitors. The wholesaleaccess-based competitors have brought consumers low prices after a politicalregulatory equilibrium of high and cross-subsidized prices in the monopoly era prior to liberalization. This price effect has given these entrants popularity and political clout. In the current situation these entrants have made sunk investments related to the implementation of wholesale access in particular, and those investments are now threatened with stranding by NGN investments of the incumbent and of infrastructure-based competitors. Thus, while the incumbent and the other infrastructure-based competitors would like to see NGN investments unregulated, the wholesale-access-based competitors would like to see regulation extended to NGN in such a way that these competitors i) do not lose their sunk investments and ii) stay competitive in the new environment. Even though incumbents also cannot re-use all their legacy investments for the NGN infrastructure, they internalize stranding in their NGN investment decision (meaning that the Arrow effect is balanced by the Schumpeter effect).

In terms of interest-group theory the existence of wholesale access regulation can be seen as a victory of access seekers and of end-users, who benefit from low downstream prices. While end-users often form a fairly weak interest group vis-àvis the regulator, they are often well-represented in the telecommunications laws that specify the long-run interests of end-users as a main legal objective (see footnote 2). This can mean that the objective of consumer welfare can dominate the objective of innovative investment (Vogelsang, 2017). This held in particular at the beginning of access regulation, when the objective of (wholesale-accessbased) competition and low end-user prices dominated, because previous prices 
were viewed as exaggerated. The interests of incumbents with large sunk investments and of other infrastructure-based suppliers have at the time been taken care of by assuring that wholesale access prices cover costs.

The emergence of NGN has been accompanied by new EC policies (European Commission, 2013; 2016a) that changed the objective from more static consumer welfare to innovative investment. Part of the reason for this change may have been triggered by East-Asian examples of NGN deployment that suggested a lack of European competitiveness on a World scale. This changed situation strengthened (or was a result of a strengthening of) the interests of incumbents and other infrastructure-based suppliers relative to access seekers and end-users. Since access seekers have substantial sunk investments, their interests are acknowledged in the EU in continued wholesale access regulation of the legacy copper network and a non-discrimination provision for wholesale NGN access.

The economic theory of regulation assumes that regulators are politicians, whose main objective is to become (re)elected. Regulators, however, are often bureaucrats, whose main objective is a large and sustained bureaucracy (Niskanen, 1971). For such regulators continued regulation that requires substantial regulatory input is valued most. The bureaucratic objective of their own survival and growth is severely threatened by the emergence of NGN. NGN (along with its mobile broadband equivalents) will eventually fully replace legacy copper networks. Thus, if wholesale access regulation cannot be transferred from copper networks to NGN the position of regulators is in danger of being eliminated. This could happen if the new service were naturally competitive or if the old and the new service were to compete side by side well into the future. In view of the developments surrounding NGN and mobile broadband this is probably the 
greatest threat to regulators (Vogelsang, 2016). This would be compatible with the Grajek and Röller (2012) interpretation of their empirical result, which is that regulators increase regulation in response to increased investments by the regulated firm.

Besides valuing continued regulation bureaucratic regulators are affected by the aforementioned and other interest groups, because politicians interfere if their favourite groups are disadvantaged by the regulators and because interest groups can invest heavily in lobbying the regulatory consultation process. This picture is enriched by the interaction across the different layers of regulation in the different member states. On one side, the EC and the Body of European Regulators for Electronic Communications (BEREC) have substantial influence in this process issuing guidelines, regulations and recommendations that aim at a greater level of harmonization in EU member states. On the other side, national regulators are going to be affected by other regulators due to peer effects induced by a high number of regulators implementing a certain policy.

Summarizing, a few normative theoretical and empirical contributions analyse the NGN investment and migration incentives related to access regulations. None of the studies examines the determinants of NGN regulation. As regards the contributions of the older positive theoretical literature, there has been no attempt made so far to examine empirically their predictions based on path dependence or interest-group behaviour in view of regulatory measures underlying old and new broadband infrastructure. From the older theory of regulation, however, the positive approach more likely induces path dependence than the normative approach leading to a different market outcome. This work intends to fill these gaps. 


\section{Testable hypotheses}

From the review of the normative and positive literature the following testable hypotheses can be drawn.

If regulators tried to maximize welfare and if maximizing welfare in a dynamic sense meant an increased emphasis on NGN investment ${ }^{5}$ then regulators would largely keep NGN infrastructure free of regulation and would announce this beforehand and, in addition, include some commitment device.

Based on an assessment of the essential facilities doctrine, duplication of NGN access infrastructure already justifies an absence of access regulation in competitive areas. In monopolistic NGN areas duplication in the form of substitute services could come from legacy networks provided they offer services from an independent competitor. As a consequence, if only the incumbent owns NGN infrastructure and is thus found to be dominant then a continuation of wholesale access regulation of the legacy infrastructure may be warranted in order to preserve competition with NGN. Competition from mobile networks (referred to as "fixed-to-mobile substitution") is another relevant determinant for wireline NGN regulations because of its crucial impact on (de-)regulation as infrastructure-based competition from mobiles ultimately results in competitive areas.

\footnotetext{
${ }^{5}$ As indicated in the introductory section, we assume that additional NGN investment translates into higher welfare (net of static inefficiencies) in view of expected externalities and the empirical evidence based on the older broadband related literature. However, we admit that it is not fully clear that favouring NGN investment is welfare enhancing in all cases.
} 
If regulators aim to maximize investment the following hypotheses related to NGN investment, NGN market structure and mobile competition thus emerge:

H1 (normative literature): NGN investment will be negatively related to the probability of NGN regulation, as regulators would refrain from heavy regulation in competitive areas (high infrastructure investment), in particular, when controlling for the market share of the dominant operator. Furthermore, the existence of well-established legacy access regulations should - controlling for NGN market structure lower the probability of NGN regulations because of a higher competitive intensity due to regulatory-induced competition. As regards NGN market structure high concentration levels will increase the probability of NGN regulation in view of economic efficiency and the linkage between market dominance and asymmetric access regulation embedded in the EU regulatory framework. Finally, high levels of fixed-to-mobile substitution should decrease the probability of NGN regulation, as mobile broadband provides a reasonable outside option to consumers and thus constrains market power of regulated operators. Since, as time progresses fixed-to-mobile substitution gains importance both for fixed legacy networks and NGN, the move towards NGN deregulation of these infrastructures should accelerate.

Because path dependence is, by definition, history driven whereas efficient decision making is always forward looking, path dependence of regulation of legacy and NGN infrastructure would typically deviate from the efficient outcomes. 
Whereas efficiency-oriented regulators would fully deregulate NGN and legacy infrastructures in competitive areas with infrastructure-based competition and would apply legacy regulation only in order not to hamper investment incentives, path-dependent regulators would simultaneously apply legacy regulation plus NGN access regulations. Path dependence that would differ from the above efficient or investment-inducing outcomes would indicate continued dominance of the interest groups that governed legacy regulation and/or dominance of bureaucratic objectives of regulators. It would be favoured by wholesale access seekers, regulators at national and EU level and, to some extent, by end-user groups, for example by those not likely to switch to NGN in the near future.

Furthermore, the EU as a bureaucracy increases its institutional power by enforcing harmonization of regulatory policies across EU member states. In order to realize this, the EU regulatory framework is designed to establish a common and harmonized regulatory approach in EU member states which contain some explicit and implicit rules to "incentivize" harmonization and "punish" deviating regulators by requiring stronger proof of evidence under the consultation and notification procedures (European Commission, 2002a, Art 7; Renda, 2016).

Hence, as a result of interest group behaviour, bureaucratic objectives of regulators and the EU the following hypotheses related to regulatory path dependence and implementation process emerge:

H2 (positive literature): Regulatory path dependence would be expressed by a positive impact of the extent and strictness of wholesale access regulations imposed in the old broadband markets on the probability of NGN access regulation. The EC's goal of 
maximizing harmonization would be expressed by a strong pressure of regulators in implementing its framework and not to fall behind the regulatory implementation process in other EU member states. NGN investment will be positively related to the probability of NGN regulation, as regulators have strong ex post expropriation incentives in case of high investment. They will thus lower access prices in order to increase consumer surplus and to improve regulators' public perceptions. In turn, if NGN investment is low, regulators feel obliged to induce further investment by lowering regulation by increasing access prices.

\section{Econometric specification and identification strategy}

\subsection{Econometric specification}

In order to test the hypotheses presented in Section 3, our estimating model, in which NGN regulation is expressed by a binary outcome indicator for EU member state $i$ and year $t$ is related to a vector of regressors $\boldsymbol{X}$ (and $\boldsymbol{\beta}$ a corresponding coefficient vector), reads as follows:

$$
N G N \_ \text {regulation }{ }_{i t}=I\left(\mathbf{X}_{\mathbf{i t}}^{\prime} \boldsymbol{\beta}+\varepsilon_{i t}>0\right)
$$

Note that our outcome variable measuring NGN regulation takes on two unique values, 0 and 1 . The value 0 denotes no NGN regulations imposed and 1 denotes that at least some kind of NGN access regulation is imposed in member state $i$ in year $t . l(\cdot)$ is an indicator function taking the value one (meaning regulation is imposed) if the latent (unobservable) variable $\boldsymbol{X}^{\prime} \boldsymbol{\beta}+\varepsilon$ is positive and zero 
otherwise. The special case of a probit model has $\varepsilon \sim N(0,1)$ and the model we wish to fit is:

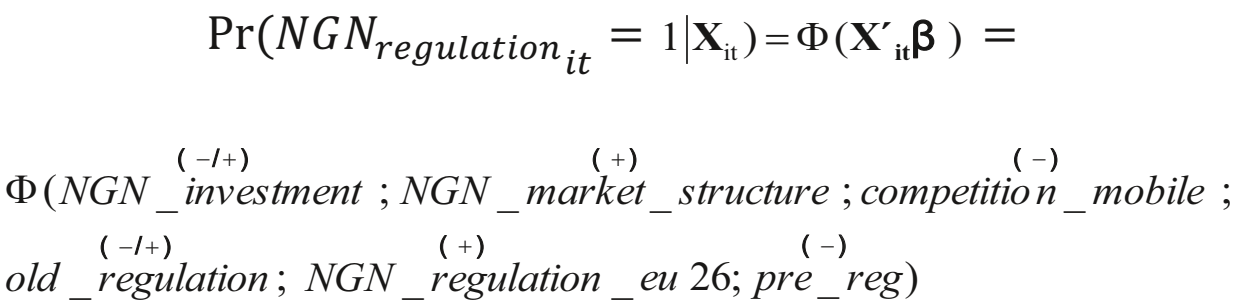

where $\Phi$ is a cumulative density function of $\varepsilon$ which is the standard cumulative normal in case of the probit model. Expected signs (in superscript round brackets) are based on the assumption of investment maximizing regulators and on the aggregate influence of selfish interest groups as expressed in $H 1 / H 2$, respectively. In Equation (2) we first control for the role of NGN investment and NGN market structure as well as for competition stemming from mobile networks (fixed-tomobile substitution). Second, NGN specific access regulation is related to a set of old broadband access regulations as well as NGN regulations in all other ("nonfocal") EU26 member states. The latter variable captures the idea that NGN regulation in member state $i$ will also be influenced by the implementation of NGN regulation in other member states $(j \neq i)$. Thirdly, pre_reg takes on two unique values and captures the period before (pre_reg $=1)$ and after $($ pre_reg $=0)$ NGN regulation became effective in EU member states. As will be outlined in the subsection below, the vector of regressors $\boldsymbol{X}$ must be divided into a vector of (potentially) endogenous regressors $\boldsymbol{X}^{\text {end }}$ and a vector of exogenous regressors $X^{\text {exog }}$ 


\subsection{Identification strategy}

In view of our baseline specification in Equations (1) and (2) we have to consider NGN investment and NGN market structure as potentially endogenous, because they will be influenced by (past, current or expected) access regulations as indicated in the related literature; also, old broadband regulations might be endogenous, even though these have been implemented typically years before regulators first imposed NGN regulations; regulators might react for instance with deregulatory approaches as regards old access infrastructure when newly imposing or revising NGN regulations.

Endogenous relations are partly mitigated as argued in Grzybowski (2005:55-56), because regulators react to demand and supply shocks typically with substantial delay caused by the legislative and technical implementation process; accordingly, there should be no contemporaneous feedback mechanisms. However, to ensure identification of causal effects we apply various sources of exogenous variation for all potentially endogenous regressors using the following three estimators:

First, we apply a control function (CF) method which is feasible in this context as our endogenous regressors are continuous, rather than binary, discrete, or censored. Similar to two-stage-least squares (2SLS) estimation, CF estimators first estimate the model of endogenous regressors as a function of all included and excluded instruments, and derive fitted values of the errors. These errors are then used as an additional regressor in the main model. These two-step estimates are obtained using Newey's (1987) minimum chi-squared (two-step) estimator and more general than maximum likelihood as the first stage function can be 
semiparametric or nonparametric. The main advantage of the two-step estimator is, however, computational, because it does not require numerical search routines. This is of particular relevance in case of several endogenous variables. ${ }^{6}$ Given an index function $I(\cdot)$ and a set of exogenous and endogenous regressors, $\boldsymbol{X}^{\text {endog }}$ and $\boldsymbol{X}^{\text {exog }}$, respectively, the CF approach can be written as follows:

$$
\begin{gathered}
N G N_{-} \text {regulation }{ }_{i t}= \\
I\left(\mathbf{X}_{\mathrm{it}}^{\mathrm{endog}} \boldsymbol{\beta}_{\mathrm{endog}}+\mathbf{X}_{\mathrm{it}}^{\mathrm{ex} o g} \boldsymbol{\beta}_{\mathrm{exog}}+\varepsilon_{i t} \geq 0\right) \\
\mathbf{X}_{\mathrm{it}}^{\mathrm{endog}}=\mathbf{Z}_{\mathrm{it}} \alpha+e_{i t}
\end{gathered}
$$

where $\boldsymbol{Z}_{i t}$ is a vector of included and excluded instruments which are related in the first stage to the vector of endogenous regressors $X^{\text {endog }}$. Residuals are estimates of $e_{i t}$ which is then plugged in the index function:

$$
I\left(\mathbf{X}_{\mathrm{it}}^{\text {endog }} \boldsymbol{\beta}_{\text {endog }}+\mathbf{X}_{\mathrm{it}}^{\text {exog }} \boldsymbol{\beta}_{\text {exog }}+\lambda e_{i t}+v_{i t} \geq 0\right)
$$

Equation (4) represents a traditional probit model controlling for $e_{i t}$ with independent normal error $v_{i t}$. Note, however, that the CF approach requires that the first stage model is correctly specified to obtain consistent estimates.

For the case that this condition does not hold we estimate a linearized version of Equation (2) by the linear probability model (LPM), i.e. by employing standard linear 2SLS ignoring the binary nature of our outcome variable. Despite the well-

\footnotetext{
${ }^{6}$ One could also make use of the maximum likelihood method and the underlying index function approach to estimate the parameters in Equation (1) and (2). In our case a maximum likelihood estimator shows, however, substantial difficulties to converge with multiple endogenous regressors.
} 
known flaws of the LPM it is attractive due to its straightforward interpretation and as its computational implementation enables all standard post-estimation diagnostics (not available in the CF approach).

As a third estimator we employ the Arellano-Bond estimator (Arellano and Bond, 1991) that allows us to account for serial correlation in the data, while still staying in the LPM framework. While our prime objective is to detect path dependence across regulations underlying old and new (NGN) broadband regulations (Equation (2)), there exists most likely yet another underlying dimension of path dependence. When regulators take a decision on NGN regulation in a certain year that decision is likely to stay in place for several years. Because of institutional rigidities in the regulatory decision making process adjustment is in fact expected to be gradual only. The Arellano-Bond $(A B)$ estimator addresses serial correlation and allows identifying both dimensions of path dependence related to NGN regulations. Doing so helps saturate the model, as the lagged dependent variable is likely to explain a large part of the variation in the dependent variable. One can then also estimate the long-run effect of the independent variables. ${ }^{7}$ Including a lagged dependent variable is not, however, enough to estimate its coefficient consistently even in a panel context as the lagged dependent variable is correlated with the error term (Cameron and Trivedi, 2005, p. 764). In order to address this

\footnotetext{
${ }^{7}$ One could model a partial adjustment mechanism, where the long-run effect of the independent variables would be obtained by dividing the coefficient estimates of the independent variables by one minus the coefficient estimate of the lagged dependent variable. The idea is that an increase in an independent variable will affect the dependent variable this period and also next period through the lagged dependent variable, so that adjustment takes place but not instantaneously.
} 
source of endogeneity, $A B$ estimation is based on the first difference transformation:

$$
\begin{aligned}
N G N_{\text {regulation }_{i t}}- & N G N_{\text {regulation }} \text { it }-1 \\
= & \beta\left(N G N_{\text {regulation }}{ }_{i t-1}-N G N_{\text {regulation }_{i t-2}}\right) \\
+ & \left(\mathbf{X}_{\mathbf{i t}}^{\mathbf{e n d o g}}-\mathbf{X}_{\mathbf{i t}-\mathbf{1}}^{\mathbf{e n d o g}}\right) \boldsymbol{\beta}_{\mathbf{e n d o g}}+\left(\mathbf{X}_{\mathbf{i t}}^{\mathbf{e x o g}}-\mathbf{X}_{\mathbf{i t}-\mathbf{1}}^{\mathbf{e x o g}}\right) \boldsymbol{\beta}_{\mathbf{e x o g}} \\
& +\left(\alpha_{i}-\alpha_{i}\right)+\left(\varepsilon_{i t}-\varepsilon_{i t-1}\right)
\end{aligned}
$$

The $A B$ estimator is then derived within a generalized method of moments (GMM) framework (Cameron and Trivedi, 2005, pp. 763-766) and reads as follows:

$$
\widehat{\boldsymbol{\beta}_{\boldsymbol{A B}}}=\left[\left(\sum_{i=1}^{N} \widetilde{\boldsymbol{X}^{\prime}}{ }_{\imath} Z_{i}\right) \boldsymbol{W}_{N}\left(\sum_{i=1}^{N} \boldsymbol{Z}_{i}^{\prime}{\widetilde{\boldsymbol{X}^{\prime}}}_{\imath}\right)\right]^{-1}\left(\sum_{i=1}^{N} \widetilde{\boldsymbol{X}^{\prime}}{ }_{\imath} Z_{i}\right) \boldsymbol{W}_{N}
$$

Adjusting the interpretation of the matrices to the current context, the matrix $\widetilde{\boldsymbol{X}^{\prime}}{ }_{l}$ is a $(T-2) \times(K+1)$ matrix with $t$-th row $\left(\Delta y_{i, t-1}, \Delta \mathbf{x}_{i t}^{\prime}\right), \mathrm{t}=3, \ldots T, \tilde{\mathbf{y}}_{i}$ is a $(T-2) \times 1$ vector with $t$-th row $\Delta y_{i, t}$, where $y_{i, t}$ is $\mathrm{NGN}$ regulation and $\mathbf{x}_{i t}^{\prime}$ includes endogenous regressors and exogenous regressors. $\boldsymbol{W}_{N}$ is the optimal two-steps weighting matrix and $Z_{i}$ is a block diagonal $(T-2) \times r$ matrix of included and excluded instruments:

$$
\left[\begin{array}{ccc}
\mathbf{z}^{\prime}{ }_{i 3} & \cdots & \mathbf{0} \\
\vdots & \ddots & \vdots \\
\mathbf{0} & \cdots & \mathbf{z}^{\prime}{ }_{i T}
\end{array}\right]
$$

In our case $\mathbf{z}_{i t}^{\prime}=\left[y_{i, t-2}, y_{i, t-3}, \ldots y_{i, t-5,} \Delta \mathbf{x}_{i t}^{\prime}, \Delta \mathbf{x}_{i t-1}^{\prime}, \mathbf{x}_{i t-1}^{\prime}, \ldots\right]$, where we inserted our external instruments and their first differences in place of our endogenous 
variables. ${ }^{8}$ The initial AB estimator (Arellano and Bond, 1991) is called "difference GMM" which has been further developed by Arellano and Bover (1995) and Blundell and Bond (1998). The augmented version of the AB estimator builds on a system of two sets of equations - the original equation in levels and the transformed one in first differences - which allows a substantial improvement in efficiency and is called "system-GMM".

\section{Data}

We employ an unbalanced panel data set of EU27 member states for the period from 2003-2015. In constructing our panel we use the following main data sources: First, for our dependent variables measuring NGN regulation, we refer to mandated NGN access regimes based on the public notifications of EU member states under Art 7 and Art 7a of the framework directive (European Commission, 2002a). In addition, we use data from WIK (2012) and some individual data provided by BEREC on request of the authors as well as from a BEREC report (BEREC, 2016). Second, the EC's "Progress Report on the Single European Electronic Communications Market" in conjunction with its "Digital Agenda Scoreboard" provides yearly data on old wholesale broadband access regulations. Our third main source is the database of FTTH Council Europe, which includes annual numbers of deployed NGN fiber lines for the EU27 member states.

All sources and variable definitions are listed and described in detail in Table A.1, while descriptive statistics are provided in Table A.2 in the Annex. Section 5.1 and

\footnotetext{
${ }^{8}$ For simplicity of notation we do not distinguish in the $x_{i t}{ }^{\prime} s$ between the included and excluded instruments.
} 
Section 5.2 below describe our dependent and independent variables, respectively. Instrumental variables are described separately in Section 5.3. Owing to the fact that some values are missing, ${ }^{9}$ there are fewer observations than the maximum number $\left(27^{*} 13=351\right)$ and some $0.71 \%$ of all the raw data were calculated using linear interpolation or had to be extrapolated.

\subsection{Dependent variable}

As indicated in the introductory section, the regulatory remedies dealing with access to NGN fall into two broad categories, symmetric and asymmetric. Symmetric regulations are imposed irrespective of market dominance positions on all network operators and typically represent interventions which grant physical access to civil engineering infrastructure, in particular, to ducts. A closer examination, however, reveals that - while some ducts are owned by other companies, such as electric utilities - most of the relevant ducts are owned by incumbents, leading to a de facto asymmetric policy. Traditional asymmetric regulations, in turn, require only the dominant (incumbent) operators to provide forms of wholesale-based access to their physical network infrastructure such as so-called access to the "unbundled" fiber loop or wholesale "bitstream" broadband access; the latter enables less scope for technological product differentiation, but

\footnotetext{
${ }^{9}$ In particular, values on old broadband access regulations are missing for Eastern European countries in the early phase of our period of analysis (years from 2003 to 2006), as these countries entered the EU at later stages and thus were not subject to the EU regulatory framework and obliged to report data before. Hence, missing values are related to political decisions but not to NGN regulations or NGN deployment.
} 
represents a much less cost-intensive business model for wholesale-accessbased operators.

According to this ambiguity underlying the delineation of (a-)symmetric regulations, we measure NGN access regulation with two different categorical variables: First, ngn_wba is a binary indicator variable that measures if and since when traditional asymmetric NGN regulations have been effectively made available as mandatory wholesale broadband access. It takes on the value one for the year when asymmetric NGN access regulation was implemented for the first time in a certain member state as well as for all succeeding years (unless the remedy has been withdrawn later on by the regulator), and zero otherwise. Second, ngn_reg is another binary outcome which includes all asymmetric wholesale access regulations as captured by the variable ngn_wba as well as symmetric duct access. For reasons outlined above, one can interpret both outcome variables as describing the existence of access regulations based on a narrow or a broader definition of NGN regulation. These alternative definitions are part of our robustness analysis.

Figure 1 shows the relevance of NGN access regulations in EU27 member states and its development during our period of analysis. As can be seen, NGN regulations have been imposed in 2007 in some member states for the first time with a strong increase in the number of symmetric and asymmetric NGN regulations since then. At the end of our period of analysis (2014-2015) we observe a total of about 70 NGN regulations implying that on average every member state imposed more than two kinds of NGN regulations. 


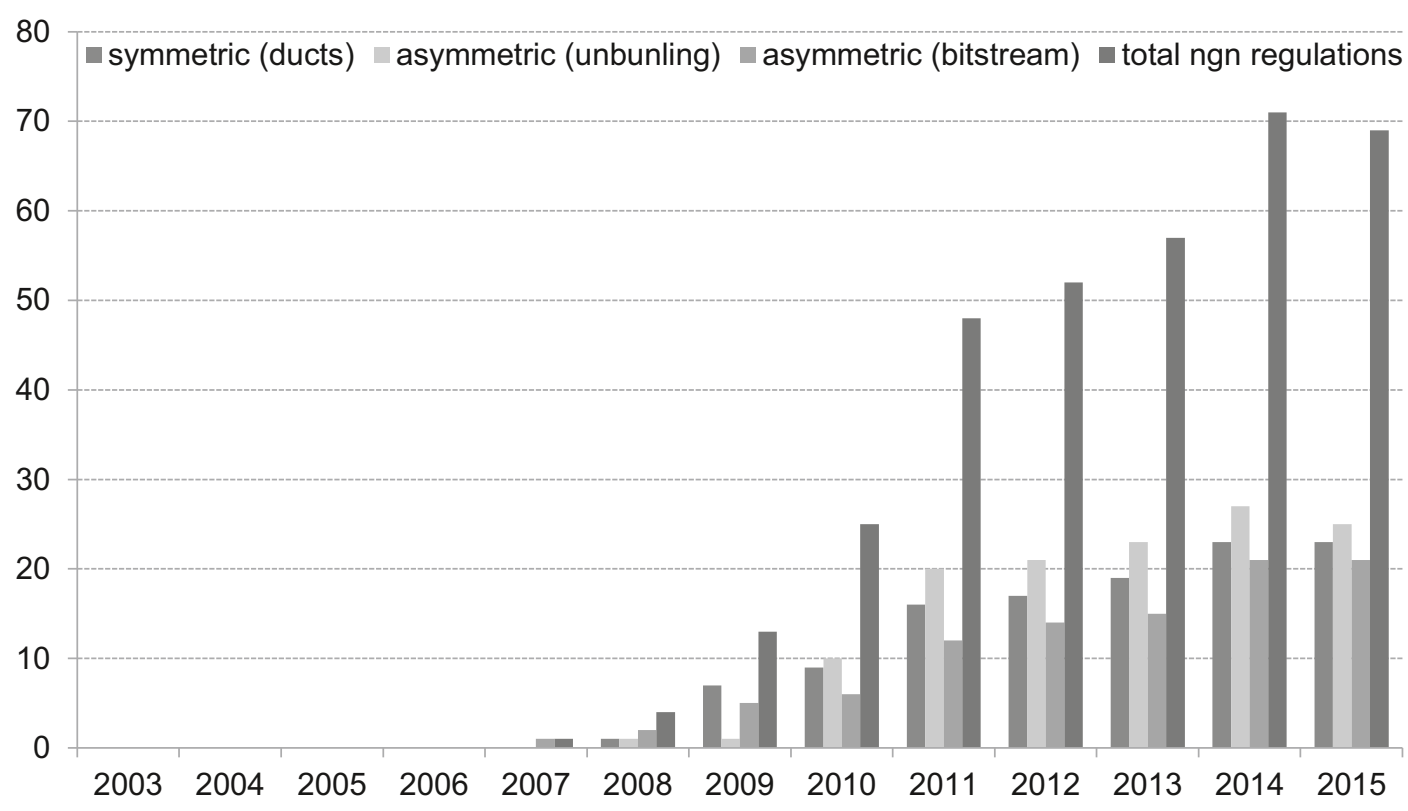

Figure 1: Relevance (absolute numbers) of imposed NGN access regulations in EU27

\subsection{Independent variables}

"Old" broadband access regulation is measured first by the effectiveness of wholesale broadband access-based competition, wba_sh, which is the share of regulated and actually used "old" wholesale broadband lines related to the total number of retail DSL broadband lines (Bacache et al., 2014; Briglauer, 2015). This indicator varies continuously from 0 to 1 and is based on "local loop unbundling" (LLU), "shared access", "bitstream" and "resale" access obligations which are made available under the EU regulatory framework. This share can also be interpreted to measure the strength of entrants as an interest group that favours the extension of wholesale access regulations. Figure 2 provides evidence on the relative importance of individual access regulations in terms of EU averages over a decade of access regulations. From this we infer that LLU based access is by far the most relevant mode of wholesale broadband access. 
Second, while we have no data on NGN access prices, we have data on the monthly unbundling access price, denoted Ilu_price, which represents the most important access remedy in view of NGN migration incentives and is directly set by the regulators. Note that whereas the variable wba_sh captures the effectiveness of legacy broadband regulations by linking these to the corresponding market outcomes, the regulated wholesale access prices are not directly linked to market outcomes and thus do not provide any information on the effectivity of the remedy. Indeed, even very low access prices might be ineffective in view of a large number of technical annex regulations which serve as a prerequisite for effective wholesale regulations. However, controlling for access prices allows us an assessment of causal effects which are directly related to regulatory policy decisions imposed on the legacy network.

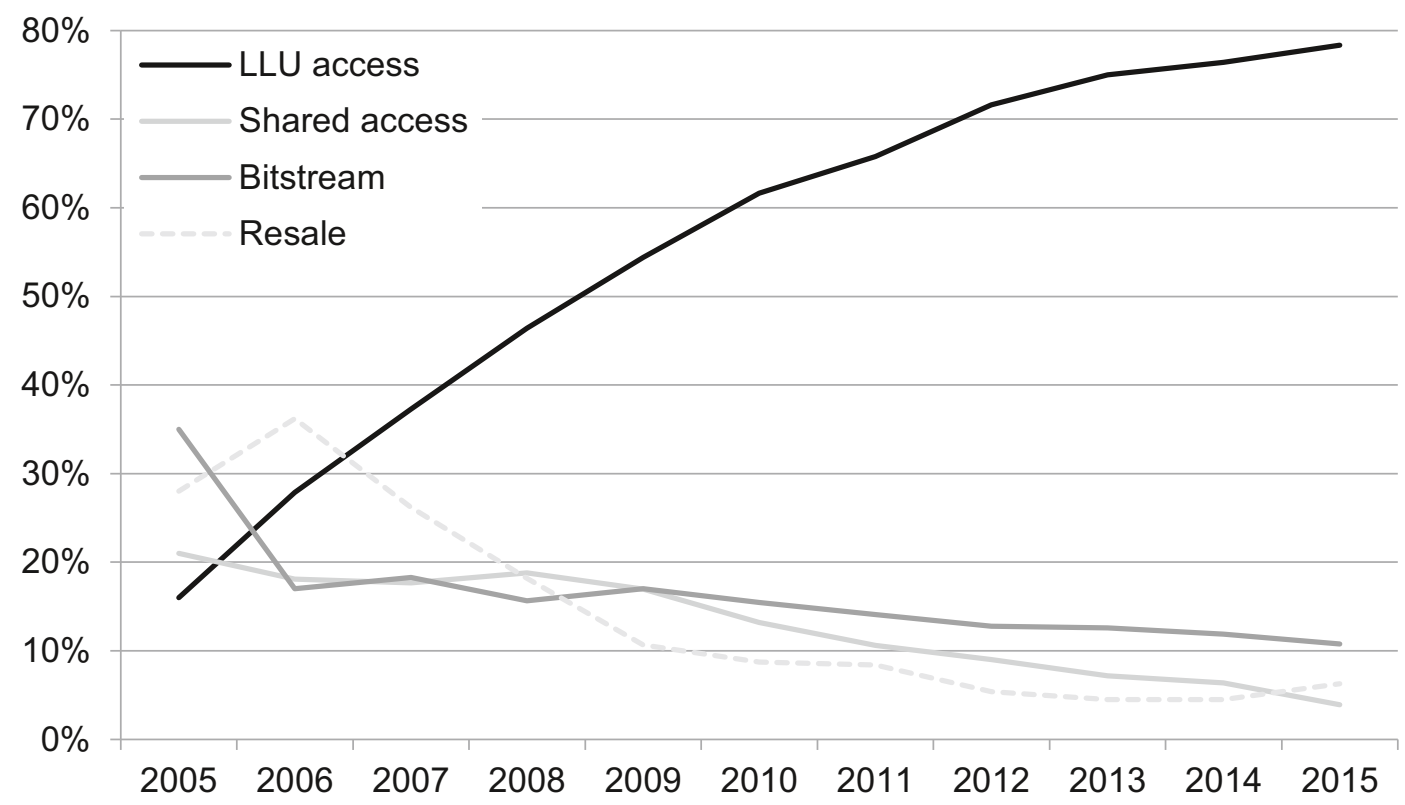

Figure 2: Relevance (\%) of old broadband access regulations in the EU 
Whereas old broadband regulations are expected to capture regulatory path dependence, NGN regulation in other EU member states is expected to represent the harmonization pressure from the EC on the regulators in implementing its framework (Briglauer et al., 2018). This variable is denoted with ngn_eu26, and is defined as the share of EU countries (other than the focal country) in EU26 countries that already introduced asymmetric access regulation of NGN. We expect that the higher the share, the more are deviating regulators pushed to adopt similar NGN access regimes. NGN regulation imposed in all other member states is considered exogenous, as it appears quite unlikely that this variable representing the EU26 average is systematically influenced by NGN regulation in a particular member state.

Investment in new broadband networks is measured by taking the log of the total number of NGN lines deployed ("homes passed"), denoted with In_ngn_inv, which represents real fiber investment in access infrastructure in physical units and includes all relevant fiber technologies as described in the technical variable definition in Table A.1. In particular, our definition includes hybrid-fiber business cases of incumbent (Fiber-to-the-Curb/FTTC) and cable-TV operators (Fiber-tothe-node/FTTN). Note that the term homes passed refers to the number of consumers that have potential NGN access, but which do not necessarily have a corresponding retail contract.

Competition and related NGN market structure is measured on the one hand by an NGN technology based concentration index, denoted with ngn_ci, which varies continuously from 0 to 1 . It is equal to one if all NGN deployments are based on a single NGN technology (full concentration), such as the incumbents' hybrid deployment scenario which still represents the only access infrastructure that is 
subjected to asymmetric NGN access regulation. ${ }^{10}$ Lower values of the concentration index point to more competitive NGN market structures as NGN lines are then provided more equally on the basis of available NGN fiber deployment technologies. On the other hand, the variable ngn_inc_sh measures the share of the incumbents' NGN lines (mostly FTTC based) to the total number of NGN lines. Note that market shares still play a crucial role in market dominance assessments $^{11}$ and they are thus expected to also play a crucial role in determining the likelihood of NGN regulations in the EU regulatory framework.

Competition from mobile networks is denoted with fms_bb as this variable captures the phenomenon of fixed-to-mobile substitution in broadband markets. The variable $f m s \_b b$ is defined as the share of basic mobile broadband subscriptions to the total number of basic mobile and basic fixed-line broadband subscriptions and varies continuously from 0 to 1 with the upper limit indicating full substitution of fixed broadband lines. Mobile competition is considered as exogenous, as NGN regulations are targeted at wireline broadband access infrastructures, and, if at all exert only an indirect effect on fixed-to-mobile substitution via the effect of regulations on competition and the resulting retail price

\footnotetext{
10 The only current exemptions are Belgium and Finland. In Belgium the cable network is subjected to access obligations next to the incumbent infrastructure resulting in a de facto duopoly regulation (at odds with the essential facility doctrine). In Finland there are a handful of bigger incumbent operators and numerous local and regional operators, which are regulated (as a specific outcome of geographic market definitions).

11 The concept of market dominance in Art 102 TFEU and case law establishes a presumption of dominance at a $50 \%$ market share and a clear indication of dominance if market shares are greater than $70 \%$.
} 
level. However, as part of our robustness analysis, we will also examine this exogeneity assumption.

\subsection{Instrumental variables}

Our estimators (Section 4.2) employ various sources of exogenous variation:

Firstly, from the previous NGN related empirical literature we know which demand and cost-side controls have been utilized in estimating reduced form NGN investment models. In view of our baseline specification (some of) these controls thus serve as immediate instruments for estimating the impact of NGN investment in Equation (2). Demand for NGN services is inter alia driven by the intensity of consumers' use of broadband services and their affinity with ICT and Internet usage (i_iday). Consumers' needs are furthermore determined by their average education levels (edu), since higher levels of education improve e-literacy skills, which considerably increases the utility derived from NGN technologies (Briglauer, 2015; Grajek and Kretschmer, 2009). Costs of NGN investment depend on population or household density and other demographic characteristics. Urbanization (urban) is perhaps a better measure of deployment costs than household or population density, because a hypothetical move of all households to one city would not change average household density but would have a massive impact on average NGN deployment costs (BEREC, 2016, 17). Also, the housing structure, in particular the number of multi-dwelling units (mdwell_perm), crucially determines "economies of density" and thus average deployment costs (FTTH Council Europe, 2012b, 24-25).

Secondly, cost controls not only provide valid predictors for NGN investment but also shape NGN market structure as certain cost conditions favour specific NGN 
technologies and exert a strong impact on the profitability of the respective business cases of operators. In particular, high degrees of urbanization are typically correlated with lower market concentration levels, as several other nonincumbent infrastructure operators (e.g. cable operators or municipalities) will find it profitable to enter NGN markets. A high degree of newly built multiple-dwelling units favours deployment of high-end (Fiber-to-the-home/building / FTTH/FTTB) NGN scenarios as fiber can be then directly and fully deployed to the customer premise. Furthermore, NGN market structure is likely to be shaped by the old broadband market structures and competition intensity in these markets (bb_sh). In particular, NGN market structure was largely driven in the past by investments of incumbent and cable-TV operators who have been the first to upgrade their legacy infrastructure to a large extent to NGN specific bandwidth levels due to comparatively low deployment costs of hybrid (FTTC/FTTN) NGN scenarios.

Thirdly, regulation and regulatory intensity on old broadband markets can be instrumented by the corresponding development in all other (non-focal) EU member states (Ilu_eu26; wba_eu26, both variables are defined analogously to ngn_eu26) in view of our reasoning related to the regulatory implementation process in Section 3.

Finally, in the $A B$ estimation we use internal instruments for the lagged dependent variable, while for the endogenous independent variables we use the first differences of the external instruments and their lags. 


\section{Estimation results}

Table 1 reports the results of the CF model with alternative specifications based on different definitions of the dependent variable, ngn_wba and ngn_reg, and selection of controls. The bottom of Table 1 reports, as a goodness-of-fit test, the $\chi^{2}$-statistic for a Wald test. The bottom of Table 1 also reports a Wald test of the exogeneity of the instrumented variables which clearly rejects the null hypothesis of no endogeneity ( $p$-value(exog)) in all regressions. This suggests that a regular probit model would produce inconsistent results. As in the 2SLS model, the order condition for identification requires that the number of excluded exogenous variables (that is, the additional instruments) be at least as great as the number of endogenous variables. The table notes contain the lists of instruments and instrumented variables.

Although estimation results in Table 1 provide point and interval estimates of $\boldsymbol{\beta}$, the choice probabilities $\left(\operatorname{Pr}\left[n g n \_w b a\left(n g n \_r e g\right)=1 \mid X\right]\right)$ and marginal effects $\left(\partial \operatorname{Pr}\left[n g n \_w b a\left(n g n \_r e g\right)=1 \mid \mathbf{X}\right] / \partial \mathbf{X}\right)$ are typically of greater interest because they have more direct economic relevance. The latter shows how the probability that NGN regulation equals one changes when one of the regressors changes by one unit. Although the underlying $\mathrm{CF}$ two-step estimator does not allow for the derivation of marginal effects for a positive outcome, two-step estimates can still be used to determine the direction of effects and test for statistically significant relationships.

From the coefficient estimates reported in Table 1 we can infer the following: First, and in line with our normative hypotheses (H1) we find in all regression specifications that NGN market structure showing higher incumbent shares 
(ngn_inc_sh) and/or higher NGN technology concentration levels (ngn_ci) are significantly more likely to be subjected to NGN regulations. Furthermore, as regards NGN investment (In_ngn_inv) the results indicate a negative effect which is marginally significant at the $10 \%$ level in some regressions suggesting that the normative hypothesis on NGN investment dominates the positive hypothesis. In view of our positive hypotheses $(H 2)$ we do not find support with respect to the market share of old broadband access regulations (wba_sh) nor as regards the status of NGN implementation in all other member states (ngn_eu26). Insignificant estimates for the variable wba_sh might be due to opposing effects as outlined in Section 3. We find, however, a significantly negative impact of the unbundling price (Ilu_price) implying that a lower unbundling price (i.e. stricter regulation of old broadband access infrastructure) makes also NGN regulation more likely. This provides evidence on regulatory path dependence underlying old and new broadband markets in line with the predictions from positive theory of regulation. In turn, this result is clearly at odds with regulatory efficiency, as strict cost-oriented regulation of old legacy infrastructure should exert competitive pressure on NGN services and thus make regulation on emerging NGN infrastructure less relevant and likely for given levels of NGN market structure.

Finally, note that our main results appear to be robust with respect to alternative model specifications. First, our results not only hold for the more narrowly defined regulatory outcome indicator, ngn_wba in regressions (1)-(4), comprising asymmetric access obligations only, but it also carries over to a broader specification of NGN regulation which also includes symmetric (duct) regulations, ngn_reg in regressions (5)-(6). Second, our regression specifications are robust for alternative specifications of pre- and post NGN regulation periods, denoted 
pre_reg_03_08 (which is equal to one for the 2003-2008 period and zero else) and analogously pre_reg_03_10.12 The latter period dummy captures the regulatory period after the EC issued its NGN relevant recommendations (European Commission, 2010; 2013; 2014).

\footnotetext{
${ }^{12}$ Note that we cannot control for year or individual member state effects as these would give rise to perfect prediction of the binary outcome variable. For the same reason we cannot define a 20032006 pre-regulation period, although this would actually correspond to the no-NGN regulation era according to Figure 1.
} 
Table 1: Results for the control function model (coefficient estimates)

\begin{tabular}{|c|c|c|c|c|c|c|}
\hline \multirow{2}{*}{$\begin{array}{l}\text { Dep. var.: } \\
\text { Regr. nr. }\end{array}$} & \multicolumn{4}{|c|}{ nan wba (0/1) } & \multicolumn{2}{|c|}{ ngn_reg $(0 / 1)$} \\
\hline & (1) & (2) & (3) & (4) & (5) & (6) \\
\hline \multirow[t]{2}{*}{ wba_sh } & -0.089 & -6.921 & -0.789 & -2.962 & -0.284 & -4.551 \\
\hline & $(-0.01)$ & $(-0.73)$ & $(-0.07)$ & $(-0.26)$ & $(-0.04)$ & $(-0.55)$ \\
\hline \multirow[t]{2}{*}{ Ilu_price } & $-1.768^{* *}$ & $-1.638^{*}$ & $-1.921^{*}$ & $-1.882^{*}$ & $-1.652^{*}$ & -1.155 \\
\hline & $(-1.99)$ & $(-1.91)$ & $(-1.94)$ & $(-1.76)$ & $(-1.85)$ & $(-1.48)$ \\
\hline \multirow[t]{2}{*}{ In_ngn_inv } & $-1.163^{*}$ & $-1.280^{*}$ & -1.262 & -1.306 & -1.330 * & $-1.123^{*}$ \\
\hline & $(-1.66)$ & $(-1.80)$ & $(-1.54)$ & $(-1.52)$ & $(-1.84)$ & $(-1.68)$ \\
\hline \multirow[t]{2}{*}{ ngn_inc_sh } & $41.777^{* *}$ & $40.432^{\text {** }}$ & $46.067^{* *}$ & $44.845^{\star *}$ & $33.759^{* *}$ & $25.640^{*}$ \\
\hline & $(2.43)$ & $(2.42)$ & $(2.26)$ & $(2.09)$ & $(2.06)$ & $(1.82)$ \\
\hline \multirow[t]{2}{*}{ ngn_ci } & 35.176 & $37.965^{*}$ & 35.170 & 34.820 & $39.051^{*}$ & $33.840^{*}$ \\
\hline & $(1.58)$ & $(1.71)$ & $(1.19)$ & $(1.19)$ & $(1.74)$ & $(1.68)$ \\
\hline \multirow[t]{2}{*}{ ngn_eu26 } & 4.267 & -3.472 & 6.794 & -15.066 & 4.719 & -1.701 \\
\hline & $(0.76)$ & $(-0.60)$ & $(0.51)$ & $(-1.05)$ & $(0.89)$ & $(-0.35)$ \\
\hline \multirow[t]{2}{*}{$f m s \_b b$} & 13.854 & 13.679 & 13.873 & 21.828 & $17.093^{*}$ & 13.142 \\
\hline & $(1.53)$ & $(1.58)$ & $(1.33)$ & $(1.53)$ & $(1.82)$ & $(1.59)$ \\
\hline \multirow{3}{*}{$\begin{array}{l}f m s \_b b^{*} \\
\text { pre_reg_03_10 }\end{array}$} & & & & -9.597 & & \\
\hline & & & & & & \\
\hline & & & & $(-1.09)$ & & \\
\hline \multirow[t]{2}{*}{ pre_reg_03_08 } & & $-9.608^{* *}$ & & & & $-8.302^{* *}$ \\
\hline & & $(-2.33)$ & & & & $(-2.22)$ \\
\hline \multirow[t]{2}{*}{ pre_reg_03_10 } & & & 2.365 & $-12.041^{* *}$ & & \\
\hline & & & $(0.45)$ & $(-2.01)$ & & \\
\hline \multirow[t]{2}{*}{ constant } & -10.346 & -3.063 & -11.221 & 3.656 & -10.555 & -3.976 \\
\hline & $(-0.68)$ & $(-0.21)$ & $(-0.44)$ & $(0.16)$ & $(-0.73)$ & $(-0.34)$ \\
\hline$\chi^{2}$ & 21.961 & 22.476 & 20.903 & 19.184 & 20.541 & 22.680 \\
\hline$p$-value (exog) & 0.004 & 0.004 & 0.000 & 0.001 & 0.004 & 0.009 \\
\hline df (exog) & 5 & 5 & 5 & 5 & 5 & 5 \\
\hline $\mathrm{N}$ & 329 & 329 & 329 & 329 & 329 & 329 \\
\hline
\end{tabular}

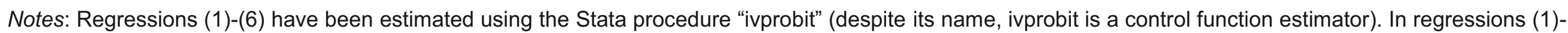
(6) we instrumented the variables wba sh, llu price, In ngn inv, ngn inc sh ngn ci using the following list of (included and) excluded instruments: (fms bb,

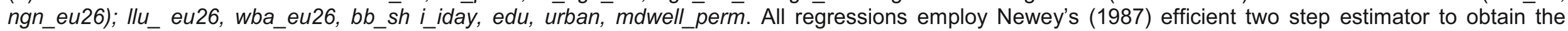
coefficient estimates and corresponding standard errors. $t$ statistics in parentheses. ${ }^{*} p<0.10,{ }^{* \star} p<0.05,{ }^{* \star \star} p<0.01$ 
Table 2 reports the marginal effects derived from the LPM. Hansen tests of overidentifying restrictions suggest that our instruments - listed in the table notes - are valid. The Kleibergen-Paap statistic suggests that there is no underidentification except for regression (1). We also report the $p$-values for the Sanderson-Windmeijer (SW) first-stage chi-squared test for the different endogenous regressors to check for underidentification of the first stage. ${ }^{13}$ As a consequence, we dropped the underidentified endogenous regressor, ngn_ci, in regressions (2)-(5). Underidentification tests confirm the relevance of the instruments. In Table 2 in regression (5) we include a linear time trend variable, trend.

Interestingly, in the LPM model path dependence in regulation is now picked up by the regulatory variable measuring the effectiveness of access broadband regulations, wba_sh. Its impact is significant and substantial in all regressions implying that an increase by one percentage point increases the probability of NGN regulation by about 0.5 percentage points. Furthermore, and in line with the results reported in Table 1 the estimated coefficients of the LPM suggest a positive and rather strong influence of the incumbent's market share, ngn_inc_sh, on the probability of NGN regulation. An increase by one percentage point increases the probability of NGN regulation by about 0.5 to 1.1 percentage points. The LPM also provides strong evidence of harmonization pressure, as measured by the variable ngn_eu26.

\footnotetext{
${ }^{13}$ Whereas standard first-stage F-tests can be used to test weakness of instruments, these tests are no longer sufficient for regression models with multiple endogenous regressors (Sanderson and Windmeijer, 2016).
} 
Table 2: Results for the linear probability model (marginal effects)

\begin{tabular}{|c|c|c|c|c|c|}
\hline \multirow{2}{*}{$\begin{array}{l}\text { Dep. var.: } \\
\text { Regr. nr. }\end{array}$} & \multicolumn{5}{|c|}{$n g n \_w b a(0 / 1)$} \\
\hline & (1) & (2) & $(3)$ & (4) & (5) \\
\hline wba_sh & $\begin{array}{c}0.636^{* *} \\
(2.31)\end{array}$ & $\begin{array}{c}0.510^{\star * *} \\
(3.59)\end{array}$ & $\begin{array}{c}0.547^{\star \star \star} \\
(4.04)\end{array}$ & $\begin{array}{l}0.411^{*} \\
(1.78)\end{array}$ & $\begin{array}{l}0.339^{*} \\
(1.66)\end{array}$ \\
\hline Ilu_price & $\begin{array}{l}0.009 \\
(0.59)\end{array}$ & $\begin{array}{l}0.014 \\
(1.23)\end{array}$ & $\begin{array}{l}0.011 \\
(0.96)\end{array}$ & & \\
\hline In_ngn_inv & $\begin{array}{l}0.004 \\
(0.24)\end{array}$ & $\begin{array}{l}-0.003 \\
(-0.30)\end{array}$ & $\begin{array}{l}-0.006 \\
(-0.54)\end{array}$ & $\begin{array}{c}-0.018^{*} \\
(-1.74)\end{array}$ & $\begin{array}{c}-0.021^{*} \\
(-1.81)\end{array}$ \\
\hline ngn_inc_sh & $\begin{array}{l}0.638^{*} \\
(1.91)\end{array}$ & $\begin{array}{l}0.557^{\star *} \\
(2.17)\end{array}$ & $\begin{array}{c}0.622^{* \star} \\
(2.36)\end{array}$ & $\begin{array}{l}1.117^{* *} \\
(2.43)\end{array}$ & $\begin{array}{l}0.951^{* *} \\
(2.40)\end{array}$ \\
\hline$n g n \_c i$ & $\begin{array}{l}-0.365 \\
(-0.63)\end{array}$ & & & & \\
\hline$f m s \_b b$ & $\begin{array}{l}-0.199 \\
(-1.07)\end{array}$ & $\begin{array}{l}-0.111 \\
(-0.85)\end{array}$ & $\begin{array}{l}0.131 \\
(0.55)\end{array}$ & & \\
\hline ngn_eu26 & $\begin{array}{c}0.786^{\star \star *} \\
(4.14)\end{array}$ & $\begin{array}{c}0.841^{* * *} \\
(5.79)\end{array}$ & $\begin{array}{c}0.553^{* *} \\
(2.04)\end{array}$ & $\begin{array}{c}0.838^{* * *} \\
(6.90)\end{array}$ & $\begin{array}{c}0.837^{* * *} \\
(3.74)\end{array}$ \\
\hline pre_reg_03_10 & $\begin{array}{l}-0.080 \\
(-0.64)\end{array}$ & $\begin{array}{l}-0.121 \\
(-1.14)\end{array}$ & $\begin{array}{l}-0.192 \\
(-1.60)\end{array}$ & & \\
\hline fms_bb* pre_reg_03_10 & & & $\begin{array}{l}-0.257 \\
(-1.20)\end{array}$ & & \\
\hline trend & & & & & $\begin{array}{l}0.007 \\
(0.23)\end{array}$ \\
\hline constant & $\begin{array}{l}-0.032 \\
(-0.08)\end{array}$ & $\begin{array}{l}-0.202 \\
(-0.82)\end{array}$ & $\begin{array}{l}-0.071 \\
(-0.27)\end{array}$ & $\begin{array}{l}-0.109 \\
(-1.05)\end{array}$ & $\begin{array}{l}-0.068 \\
(-0.78)\end{array}$ \\
\hline $\mathrm{F}$ & 80.836 & 126.125 & 104.431 & 110.244 & 142.175 \\
\hline Hansen ( $p$-value) & 0.102 & 0.106 & 0.130 & 0.245 & 0.156 \\
\hline SW Chi-sq test ( $p$-value) & & & & & \\
\hline wba_sh & 0.0533 & 0.0000 & 0.0000 & 0.0000 & 0.0000 \\
\hline Ilu_price & 0.0115 & 0.0001 & 0.0001 & & \\
\hline In_ngn_inv & 0.0345 & 0.0000 & 0.0000 & 0.0000 & 0.0000 \\
\hline ngn_inc_sh & 0.0060 & 0.0000 & 0.0000 & 0.0006 & 0.0001 \\
\hline $\begin{array}{l}\text { ngn_ci } \\
\text { fms } b b\end{array}$ & 0.2395 & & & & \\
\hline Kleibergen-Paap ( $p$-value) & 0.279 & 0.000 & 0.000 & 0.005 & 0.001 \\
\hline $\mathrm{N}$ & 329 & 329 & 329 & 329 & 329 \\
\hline
\end{tabular}

Notes: In all regressions (1)-(5) we instrumented the variables wba sh, llu price, In ngn inv, ngn inc sh, ngn ci using the following list of (included and) excluded

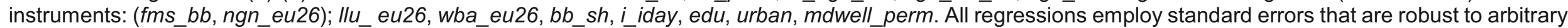
forms of heteroscedasticity and serial correlation. $t$ statistics in parentheses. ${ }^{*} p<0.10,{ }^{* *} \bar{p}<0.05,{ }^{* * *} p<0.01$ 
Finally, Table 3 reports the estimation results for the AB GMM-system estimator based on the linear probability model. Regressions (1)-(5) provide alternative specifications similar to the LPM specifications in Table 2. Note, however, that as this estimator is based on a first-differences approach (equation (5)) it also explicitly controls for any country-level fixed effects. We conduct a set of standard post estimation tests to verify if we should have any concern regarding our model specification: the $A R(1), A R(2)$ and $A R(3)$ serial correlation tests and the Hansen tests of over-identifying restrictions confirm that our identification strategy is valid.

The interpretation of the coefficient estimates in Table 3 is related to marginal effects indicating how a unit change in the regressors is changing the probability that NGN regulation is implemented. Hence, a coefficient of about 0.3 (column (2)) for the regulation on the old copper technology, wba_sh, implies that if old broadband regulation increases by one percentage point then the probability of regulation on NGN regulation increases by about 0.3 percentage points in the short run. The corresponding long run coefficient estimate $(0.3 /(1-0.55)=0.67)$ is in fact largely in line with the corresponding static LPM estimates. We observe that the effect of regulation imposed on the old broadband infrastructure is significant at the $10 \%$ level in regressions (1)-(5). Likewise, the coefficient of the variable ngn_eu26 is highly significant and exerts a substantial and positive impact on the probability of NGN regulations. The long run coefficient estimates are again close to the corresponding LPM estimates. Except for the coefficient estimates on the variable ngn_inc_sh, which appear to be insignificant in all AB regressions, LPM estimation results carry over quite well to the $A B$ model.

It is relevant to notice that we obtain these estimates even after saturating the model including the lagged dependent variable and country-level fixed effects. The 
coefficient estimate of the lagged dependent variable is highly significant and - in combination with fixed-effects - already captures a large part of the total variation in the binary dependent variable. As expected, we find that there is a strong element of path dependence from one year to the next in the regulation of NGN as it takes time to take a decision and when it is taken it typically stays in place for a longer period of time in view of the average duration of market analysis procedures. In particular, we find that after controlling for the other variables NGN regulation displays a rather narrowly estimated autocorrelation coefficient in the interval of 0.55 to 0.59 . This implies that, if NGN regulation has been in place in the previous period, there is a $55 \%$ to $59 \%$ chance to observe NGN regulation also in the current period due to this kind of regulatory path dependence..$^{14}$

\footnotetext{
${ }^{14}$ In Table 2 and Table 3 we do not explicitly report the robustness results when using ngn_reg as a dependent variable; results are, however, available upon request from the authors.
} 
Table 3: Results for the Arellano-Bond model (marginal effects)

\begin{tabular}{|c|c|c|c|c|c|}
\hline \multirow{2}{*}{$\begin{array}{l}\text { Dep. var. } \\
\text { Reg. nr. }\end{array}$} & \multicolumn{5}{|c|}{ ngn_wba(0/1) } \\
\hline & (1) & $(2)$ & $(3)$ & (4) & (5) \\
\hline Lagged dep. var. & $\begin{array}{c}0.562^{* * *} \\
(7.30)\end{array}$ & $\begin{array}{c}0.547^{\star * \star} \\
(7.75)\end{array}$ & $\begin{array}{c}0.548^{* * *} \\
(8.78)\end{array}$ & $\begin{array}{l}0.587^{* * *} \\
(11.20)\end{array}$ & $\begin{array}{c}0.573^{* * *} \\
(9.79)\end{array}$ \\
\hline wba_sh & $\begin{array}{l}0.248^{*} \\
(1.92)\end{array}$ & $\begin{array}{c}0.296^{* *} \\
(1.96)\end{array}$ & $\begin{array}{l}0.301^{* *} \\
(2.15)\end{array}$ & $\begin{array}{l}0.197^{\star} \\
(1.77)\end{array}$ & $\begin{array}{c}0.223^{* *} \\
(2.37)\end{array}$ \\
\hline Ilu_price & $\begin{array}{l}-0.005 \\
(-1.08)\end{array}$ & $\begin{array}{l}-0.004^{*} \\
(-1.68)\end{array}$ & $\begin{array}{l}-0.004 \\
(-1.60)\end{array}$ & $\begin{array}{l}-0.001 \\
(-0.35)\end{array}$ & $\begin{array}{l}-0.002 \\
(-0.24)\end{array}$ \\
\hline In_ngn_inv & $\begin{array}{l}0.005 \\
(0.96)\end{array}$ & $\begin{array}{l}0.005 \\
(0.95)\end{array}$ & $\begin{array}{l}0.005 \\
(1.05)\end{array}$ & $\begin{array}{l}0.005^{\star} \\
(1.76)\end{array}$ & $\begin{array}{l}0.005^{*} \\
(1.80)\end{array}$ \\
\hline ngn_inc_sh & $\begin{array}{l}-0.059 \\
(-0.57)\end{array}$ & $\begin{array}{l}-0.097 \\
(-0.77)\end{array}$ & $\begin{array}{l}-0.094 \\
(-0.77)\end{array}$ & $\begin{array}{l}-0.083 \\
(-0.75)\end{array}$ & $\begin{array}{l}-0.105 \\
(-0.98)\end{array}$ \\
\hline ngn_ci & $\begin{array}{l}-0.021 \\
(-0.26)\end{array}$ & $\begin{array}{l}0.009 \\
(0.17)\end{array}$ & & $\begin{array}{l}0.067 \\
(0.94)\end{array}$ & $\begin{array}{l}0.071 \\
(0.89)\end{array}$ \\
\hline ngn_eu26 & $\begin{array}{c}0.425^{* * *} \\
(4.11)\end{array}$ & $\begin{array}{c}0.449^{* * *} \\
(5.34)\end{array}$ & $\begin{array}{c}0.446^{\star * *} \\
(5.62)\end{array}$ & $\begin{array}{c}0.339^{* * *} \\
(3.41)\end{array}$ & $\begin{array}{c}0.359^{* *} \\
(2.52)\end{array}$ \\
\hline pre_reg_03_10 & & & & $\begin{array}{l}-0.073 \\
(-1.10)\end{array}$ & $\begin{array}{l}-0.073 \\
(-1.03)\end{array}$ \\
\hline$f m s \_b b$ & & & & & $\begin{array}{l}0.005 \\
(0.04)\end{array}$ \\
\hline constant & $\begin{array}{l}0.033 \\
(0.34)\end{array}$ & & & & \\
\hline $\operatorname{AR}(1)(p$-value) & 0.000 & 0.000 & 0.000 & 0.000 & 0.000 \\
\hline $\operatorname{AR}(2)$ ( $p$-value) & 0.580 & 0.592 & 0.575 & 0.984 & 0.959 \\
\hline $\operatorname{AR}(3)$ ( $p$-value) & 0.255 & 0.259 & 0.242 & 0.998 & 0.919 \\
\hline Sargan ( $p$-value) & 0.635 & 0.673 & 0.725 & 0.863 & 0.864 \\
\hline Hansen ( $p$-value) & 0.410 & 0.477 & 0.524 & 0.597 & 0.514 \\
\hline $\mathrm{N}$ & 320 & 320 & 320 & 320 & 319 \\
\hline
\end{tabular}

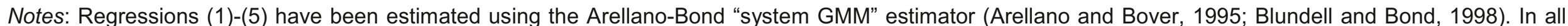

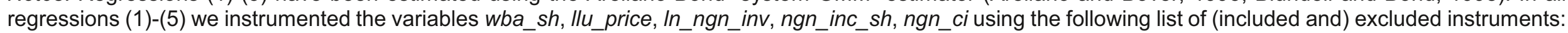
(fms bb, ngn eu26); Ilu eu26, wba eu26, bb sh, i iday, edu, mdwell perm, urban. Up to five lags of the dependent variable have been used as GMM-style instruments for the lagged dependent variable. Two-step robust standard errors allow for arbitrary forms of heteroscedasticity and autocorrelation. $t$ statistics in parentheses. ${ }^{*} p<0.10,{ }^{* *} p<0.05,{ }^{* * *} p<0.01$ 
As regards the competitive phenomenon of fixed-to-mobile substitution, we do not find any evidence for a significantly negative effect of the variable $f m s \_b b$ in all regressions in Tables 1 to 3 . This is quite remarkable given the massive dispersion of mobile broadband technologies and services during our period of analysis and since the roll-out of $4 G$ (LTE) wireless broadband in 2010 , in particular. ${ }^{15}$ According to a report of the European Commission (2016b, p. 14), 4G mobile broadband availability reached $86 \%$ as of mid-2015, up from 8\% in 2011 (Figure 3). The comparative growth in NGN broadband was much lower in the same period (from about $48 \%$ to $71 \%$ ). This competitive development clearly suggests that in terms of efficiency NGN regulation of wireline networks should have also become less likely especially during this period. For this reason regressions (4) in Table 1 and regression (3) in Table 2 include an additional term (fms_bb*pre_reg_03_10) interacting the fixed-to-mobile substitution variable (fms_bb) with a dummy controlling for the $4 \mathrm{G}$ rollout-period (pre_reg_03_10). The respective coefficient estimates still remain insignificant.

However, the empirical result can be well explained if one takes a closer look on the market analysis provisions embedded under the EU regulatory framework. To initiate market analysis cases in individual member states, the EC at irregular intervals issues a list of so-called relevant markets susceptible for sector-specific

\footnotetext{
${ }^{15}$ Estimation results remain insignificant if we treat mobile broadband, $f m s \_b b$, as endogenous using the percentage of households who possess smartphones, smphone, and laptops, laptop, as instrumental variables (the corresponding Durbin-Wu Hausman tests suggests that mobile broadband can actually be treated as exogenous). Results are available from the authors upon request.
} 
regulation. ${ }^{16}$ Regulators may then adopt the underlying definition of relevant markets as is and assess competition and dominance issues within these predefined markets. In case of regulators deviating from the EC's market definition, however, the individual regulator is confronted with a full burden of proof in terms of sound empirical analysis related to market definition which represents an informationally and time-demanding task. Accordingly, the majority of European regulators, in particular smaller and medium sized authorities, has preferred to adopt the EC's recommendation on relevant markets (Renda, 2016) which until now has excluded mobile broadband access products from the list of relevant markets (European Commission, 2014).

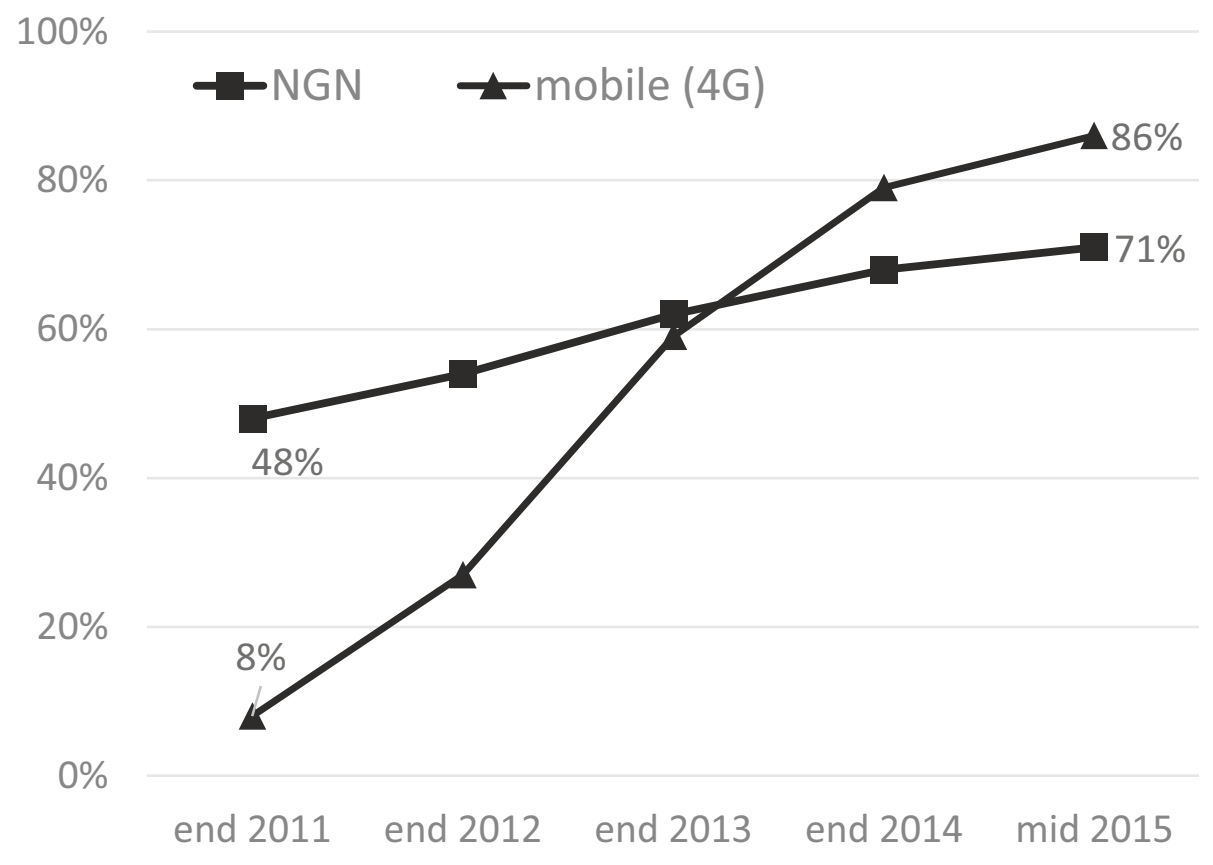

Figure 3: NGN and mobile broadband (4G/LTE) household coverage in the EU

\footnotetext{
${ }^{16}$ Since the beginning of sector-specific regulation in EU member states (1997/1998), the EC has issued three relevant market recommendations in 2002, 2007 and 2014.
} 


\section{Summary and conclusions}

To the best of our knowledge this is the first paper to examine the determinants of sector-specific EU regulation of NGN broadband infrastructure which are related to both efficiency-based objectives of regulators and the objectives of selfish interest groups and institutions. In view of our research questions we found supportive evidence on hypotheses derived from the normative and positive theoretical literature.

In particular, CF and LPM estimates point to strong evidence for the relevance of NGN market share of incumbent operators in line with the efficiency perspective embedded in the essential facilities doctrine and the market dominance concept. In contrast, all estimation results suggest that competition related to fixed-tomobile substitution appears to be an insignificant predictor for the probability of NGN regulations even when controlling for the massive diffusion of mobile broadband services since the roll-out of $4 G$ (LTE) networks. This suggests that little importance has been attached to the phenomenon of fixed-to-mobile substitution in terms of adequate empirical market analysis. Mobile broadband could enter this in three ways: First, as a relevant market of its own; second, as a service that is in the same market as fixed broadband access; third as a competitive influence on the dominance of a fixed broadband operator. Disregarding these channels can be interpreted as an indirect evidence of the ECs' harmonization objectives to push for a common adoption of EU policy recommendations - which still foresee separate wireline and wireless markets among EU member states which stipulate a necessity of fixed broadband access regulations. 
We also found direct evidence for the existence of path dependence related to the old broadband regulatory regime: The LPM and $A B$ estimators reveal path dependence underlying the variable measuring the effectiveness of access regulations and hence the impact of regulatory-induced competition pointing to the strength of alternative operators and consumers as relevant interest groups. According to the CF estimation approach (with some evidence also from the LPM estimation) a decrease in the unbundling price and NGN investment increases the probability of NGN regulations. As expected, the $A B$ model estimates also found strong evidence for path dependence underlying previous and existing NGN regulations.

Finally, the results of the linear probability and the $A B$ linear probability models also indicate the existence of strong harmonization pressure stemming from the status of NGN regulation in all other member states. This result is also compatible with the positive hypothesis related to presence of peer effects across regulators.

According to our findings the EU regulatory framework towards new broadband infrastructure exhibits indeed some inefficiencies related to regulatory state dependence, bureaucracy goals of regulatory decision makers and an insufficient consideration of competition from mobile broadband markets which presumably has led to an overemphasis of the incumbent's wireline market shares in determining positions of market dominance and consequently in determining NGN regulations. This result is also in line with the positive theoretical literature predicting higher than efficient levels of regulation.

Our results are of particular importance in view of the upcoming implementation of the recent major review of the EU communications framework (European 
Commission, 2016a) in individual member states. The latter foresees measures to considerably extend access regulations by applying the concept of market dominance even into the context of narrow oligopolies, and by expanding symmetric remedies to a potentially large number of network operators and access elements. In view of our results such developments present strong concerns as the total number of NGN regulations appear to further increase despite an ever increasing competitive intensity in broadband markets. Accordingly, any new access regulations should be subject to close scrutiny as regards their normative foundation in order to avoid inefficient over-regulations. 


\section{Annex}

Table A.1: Variable descriptions and sources

\begin{tabular}{|c|c|c|}
\hline Variable & Description & Source \\
\hline & Dependent variables & \\
\hline $\begin{array}{l}\text { Asymmetric } \\
\text { NGN regulation } \\
\text { ngn_wba }\end{array}$ & $\begin{array}{l}\text { NGN regulation including all asymmetric remedies (ngn_wba): i) } \\
\text { cost-oriented unbundling incl sub-loop unbundling (access to } \\
\text { Fiber-to-the-node (FTTN/Docsis)/Fiber-to-the-cabinet } \\
\text { (FTTC/VDSL) networks incl. virtual undbundled local access } \\
\text { (VULA)) and Fiber-to-the-home/building (FTTH/FTTB) } \\
\text { unbundling incl VULA ii) cost-oriented products based on fibre in } \\
\text { the access network (local and regional wholesale broadband } \\
\text { access to FTTN/FTTC and FTTH networks); this binary indicator } \\
\text { variable is equal to one if and since when one of the above } \\
\text { asymmetric NGN regulations have been implemented for the first } \\
\text { time in a certain EU member state (and zero else or when } \\
\text { regulation is withdrawn) }\end{array}$ & $\begin{array}{l}\text { EC, } \\
\text { WIK, } \\
\text { BEREC }\end{array}$ \\
\hline \multirow[t]{3}{*}{$\begin{array}{l}\text { (A-)symmetric } \\
\text { NGN regulation } \\
\text { ngn_reg }\end{array}$} & $\begin{array}{l}\text { NGN regulation including asymmetric and/or symmetric } \\
\text { remedies; the latter refer to cost-oriented access to ducts }\end{array}$ & $\begin{array}{l}\text { EC, } \\
\text { WIK, } \\
\text { BEREC }\end{array}$ \\
\hline & Independent variables & \\
\hline & NGN investment & \\
\hline \multirow[t]{2}{*}{$\begin{array}{l}\text { (Log of) } \\
\text { Deployed NGN } \\
\text { lines } \\
\text { In_ngn_inv }\end{array}$} & $\begin{array}{l}\text { (Logarithm of) Total number of homes passed by all individual } \\
\text { NGN technologies (=FTTH/FTTB/FTTC/FTTN). "Homes passed" } \\
\text { is the total number of premises, i.e. a home or place of business }\end{array}$ & $\begin{array}{l}\text { FTTH } \\
\text { Council } \\
\text { Europe }\end{array}$ \\
\hline & Old regulation and EU NGN regulation & \\
\hline $\begin{array}{l}\text { Price for LLU } \\
\text { Ilu_price }\end{array}$ & Monthly average total cost (=access price) for full LLU in $€$ & $\begin{array}{l}\text { EU DAE } \\
\text { Score- } \\
\text { board }\end{array}$ \\
\hline $\begin{array}{l}\text { EU LLU price } \\
\text { Ilu_eu26 }\end{array}$ & $\begin{array}{l}\text { Average EU LLU access price in all other (non-focal) EU26 } \\
\text { countries }\end{array}$ & $\begin{array}{l}\text { EU DAE } \\
\text { Scorebo } \\
\text { ard }\end{array}$ \\
\hline $\begin{array}{l}\text { Wholesale- } \\
\text { based access } \\
\text { competition } \\
\text { wba_sh }\end{array}$ & $\begin{array}{l}\text { Share of broadband lines based on old wholesale broadband } \\
\text { access regulations (unbundling, bitstreaming, resale) to total retail } \\
\text { broadband lines (based on incumbent's DSL lines, excluding } \\
\text { cable broadband lines) }\end{array}$ & $\begin{array}{l}\text { EU DAE } \\
\text { Score- } \\
\text { board }\end{array}$ \\
\hline $\begin{array}{l}\text { EU wholesale } \\
\text { broadband } \\
\text { wba_eu26 }\end{array}$ & $\begin{array}{l}\text { Average share of broadband lines based on old broadband } \\
\text { regulations in all other (non-focal) EU26 countries }\end{array}$ & $\begin{array}{l}\text { EU DAE } \\
\text { Score- } \\
\text { board }\end{array}$ \\
\hline $\begin{array}{l}\text { EU NGN } \\
\text { regulation } \\
\text { ngn_eu26 }\end{array}$ & $\begin{array}{l}\text { Share of EU countries (other than the focal country) that already } \\
\text { introduced asymmetric forms of (a-)symmetric regulation of NGN }\end{array}$ & $\begin{array}{l}\text { EC, WIK, } \\
\text { BEREC }\end{array}$ \\
\hline
\end{tabular}




\section{Competition and market structure}

\begin{tabular}{|c|c|c|}
\hline $\begin{array}{l}\text { NGN market } \\
\text { share incumbent } \\
\text { ngn_inc_sh }\end{array}$ & $\begin{array}{l}\text { Share of FTTC lines deployed by (asymmetrically } \\
\text { regulated) incumbent operators to total NGN lines }\end{array}$ & $\begin{array}{l}\text { FTTH Council } \\
\text { Europe }\end{array}$ \\
\hline $\begin{array}{l}\text { NGN technology } \\
\text { index } \\
\text { ngn_ci }\end{array}$ & $\begin{array}{l}\text { Sum of squared market shares of relevant NGN } \\
\text { technologies, ie } \sum \text { (lines based on indivudal NGN } \\
\text { technology/all NGN lines) }\end{array}$ & $\begin{array}{l}\text { FTTH Council } \\
\text { Europe }\end{array}$ \\
\hline $\begin{array}{l}\text { Entrant's market } \\
\text { share } \\
\text { bb_sh }\end{array}$ & $\begin{array}{l}\text { Alternative operator's retail market share in fixed } \\
\text { broadband lines }\end{array}$ & Eurostat \\
\hline \multirow[t]{2}{*}{$\begin{array}{l}\text { Fixed-to-mobile } \\
\text { substitution } \\
\text { fms_bb }\end{array}$} & $\begin{array}{l}\text { Share of the total number of mobile broadband } \\
\text { subscriptions (with internet access equal to } 256 \mathrm{kbit} / \mathrm{s} \text { ) } \\
\text { to the total number of mobile and fixed broadband } \\
\text { subscriptions (with internet access equal to } 256 \mathrm{kbit} / \mathrm{s} \text { ) }\end{array}$ & ITU \\
\hline & Demand control variables & \\
\hline $\begin{array}{l}\text { Education } \\
\text { edu }\end{array}$ & $\begin{array}{l}\text { Percentage of population with educational attainment of } \\
\text { secondary education or higher, population aged } 25 \text { to } 64 \\
\text { years }\end{array}$ & Eurostat \\
\hline $\begin{array}{l}\text { Internet usage } \\
\text { i_iday }\end{array}$ & $\begin{array}{l}\text { Percentage of population using internet services every } \\
\text { day }\end{array}$ & Eurostat \\
\hline $\begin{array}{l}\text { Smartphones } \\
\text { smphone }\end{array}$ & $\begin{array}{l}\text { Households that possess a smartphone as percentage } \\
\text { of all households }\end{array}$ & Euromonitor \\
\hline \multirow[t]{2}{*}{$\begin{array}{l}\text { Laptops } \\
\text { laptop }\end{array}$} & $\begin{array}{l}\text { Households that possess a laptop as percentage of all } \\
\text { households }\end{array}$ & Euromonitor \\
\hline & Cost control variables & \\
\hline $\begin{array}{l}\text { Building permits } \\
\text { mdwell_perm }\end{array}$ & $\begin{array}{l}\text { Building permits for two and more dwellings as annual } \\
\text { index normalized to } 100 \text { in } 2010\end{array}$ & Eurostat \\
\hline $\begin{array}{l}\text { Urban population } \\
\text { urban }\end{array}$ & $\begin{array}{l}\text { Population of a country that lives in an urban } \\
\text { environment as percentage of the total population }\end{array}$ & MarketLine \\
\hline
\end{tabular}


Table A.2: Summary statistics

\begin{tabular}{|c|c|c|c|c|c|}
\hline & Obs & Mean & Std. dev. & Min & Max \\
\hline \multicolumn{6}{|l|}{ Dep. vars.: } \\
\hline$n g n \_w b a$ & 351 & 0.399 & 0.490 & 0 & 1 \\
\hline ngn_reg & 351 & 0.439 & 0.497 & 0 & 1 \\
\hline \multicolumn{6}{|l|}{ Regulatory vars.: } \\
\hline wba_sh & 335 & 0.193 & 0.193 & 0 & 0.970 \\
\hline Ilu_price & 335 & 11.43 & 4.623 & 5.110 & 42 \\
\hline \multicolumn{6}{|l|}{ Market structure vars. } \\
\hline In_ngn_inv & 346 & 10.57 & 5.952 & 0 & 18.20 \\
\hline ngn_inc_sh & 346 & 0.243 & 0.273 & 0 & 1 \\
\hline ngn_ci & 346 & 0.508 & 0.333 & 0 & 1 \\
\hline$f m s \_b b$ & 336 & 0.548 & 0.191 & 0.075 & 0.991 \\
\hline fms_bb*pre_reg_03_10 & 336 & 0.280 & 0.276 & 0 & 0.991 \\
\hline \multicolumn{6}{|l|}{ Harmonization var.: } \\
\hline ngn_eu26 & 351 & 0.399 & 0.396 & 0 & 1 \\
\hline \multicolumn{6}{|l|}{ Excluded instr.: } \\
\hline Ilu_eu26 & 335 & 11.43 & 3.124 & 8.817 & 19.86 \\
\hline wba_eu26 & 335 & 0.193 & 0.0189 & 0.146 & 0.246 \\
\hline$b b \_s h$ & 337 & 0.507 & 0.158 & 0 & 1 \\
\hline i_iday & 351 & 0.698 & 0.143 & 0.250 & 0.950 \\
\hline$e d u$ & 351 & 73.86 & 15.94 & 19.80 & 93.50 \\
\hline urban & 351 & 72.87 & 12.09 & 49.65 & 97.86 \\
\hline mdwell & 351 & 145.9 & 123.6 & 10.92 & 913.1 \\
\hline smphone & 312 & 21.864 & 21.620 & 0.3 & 77 \\
\hline laptop & 312 & 34.201 & 23.809 & 0 & 87.5 \\
\hline
\end{tabular}




\section{References}

Areeda, P. (1989). Essential Facilities: An Epithet in Need of Limiting Principles. Antitrust Law Journal 58, 841.

Arellano, M., \& Bond. S. (1991). Some tests of specification for panel data: Monte Carlo evidence and an application to employment equations. The Review of Economic Studies 58, 277-97.

Arellano, M., \& Bover, O. (1995). Another look at the instrumental variable estimation of error-components models. Journal of Econometrics 68, 2951.

Bacache, M., Bourreau, M., \& Gaudin, G. (2014). Dynamic Entry and Investment in New Infrastructures: Empirical evidence from the Fixed Broadband Industry. Review of Industrial Organization 44, 179-209.

Becker, G.S. (1983). A theory of competition among pressure groups for political influence. The Quarterly Journal of Economics 98, 371-400.

Bertschek, I., Briglauer, W., Hüschelrath, K., Kauf, B. \& Niebel, T. (2016). The Economic Impacts of Broadband Internet: A Survey. Review of Network Economics 14(4), 201-227.

BEREC (2016). Challenges and drivers of NGA rollout and infrastructure competition (BoR(16) 96).

Bourreau, M., Cambini, C., \& Dogan, P. (2012). Access Pricing, Competition, and Incentives to Migrate From "Old" to "New" Technology. International Journal of Industrial Organization 30, 713-723.

Bond, S. (2002). Dynamic panel data models: A guide to micro data methods and practice. Working Paper 09/02. Institute for Fiscal Studies, London. 
Blundell, R., \& Bond. S. (1998). Initial conditions and moment restrictions in dynamic panel data models. Journal of Econometrics 87, 115-43.

Briglauer, W. (2015). How EU sector-specific regulations and competition affect migration from old to new communications infrastructure: recent evidence from EU27 member states. Journal of Regulatory Economics 48(2), 194217.

Briglauer, W., Frübing, S. \& Vogelsang, I. (2015). The Impact of Alternative Public Policies on the Deployment of New Communications Infrastructure - A Survey. Review of Network Economics 13(3), 227-270.

Briglauer, W., Cambini, C. \& Grajek, M. (2018). Speeding Up the Internet: regulation and Investment in the European Fiber Optic Infrastructure. International Journal of Industrial Organization (forthcoming).

Cambini, C., \& Jiang, Y. (2009). Broadband Investment and Regulation: A Literature Review. Telecommunications Policy 33, 559-574.

Cameron, A., \& Trivedi, P. (2005). Microeconometrics Methods and Applications. Cambridge, UK: Cambridge University Press. Ch. 15, 490-528.

Cave, M., \& Feasey, R. (2017). Policy towards competition in high-speed broadband in Europe, in an age of vertical and horizontal integration and oligopolies. Project report, Centre on Regulation in Europe.

European Commission (1998). Notice on the application of the competition rules to access agreements in the telecommunications sector: Framework, Relevant Markets and Principles, 98/C 265/02 (Access Notice), Brussels. European Commission (2002a). Directive 2002/21/EC on a common regulatory framework for electronic communications networks and services (Framework Directive), Brussels. 
European Commission (2002b). Directive 2002/19/EC of the European

Parliament and of the Council of 7 March 2002 on access to, and interconnection of, electronic communications networks and associated facilities (Access Directive), Brussels.

European Commission (2010). Commission Recommendation 2010/572/EU of 20 September 2010 on Regulated Access to Next Generation Access Networks (NGA), Brussels.

European Commission (2013). Commission Recommendation of 11 September 2013 consistent non-discrimination obligations and costing methodologies to promote competition and enhance the broadband investment environment. C(2013) 5761 final, Brussels.

European Commission (2014). Commission Recommendation of 9 October 2014 on relevant product and service markets within the electronic communications sector susceptible to ex ante regulation in accordance with Directive 2002/21/EC on a common regulatory framework for electronic communications networks and services, Brussels.

European Commission. (2016a). Proposal for a Directive of the European parliament and of the Council establishing the European Electronic Communications Code (Recast).COM/2016/0590 final - 2016/0288 (COD), Brussels.

European Commission (2016b). Europe's Digital Progress Report 2016:

Connectivity - Broadband market developments in the EU, Brussels.

FTTH Council Europe (2012). The Cost of Meeting Europe's Network Needs.

Ventura Partners study available at: http://www.ftthcouncil.eu/documents/Reports/2012/Cost_Model_Report_Full_Version.pdf. 
Grajek, M., \& Röller, L.H. (2012). Regulation and Investment in Network Industries: Evidence from European Telecoms. Journal of Law and Economics 55, 189-216.

Grajek, M., \& Kretschmer, T. (2009). Usage and diffusion of cellular telephony, 1998-2004. International Journal of Industrial Organization 27, 238-249.

Grzybowski, L. (2005). Regulation of mobile telephony across the European Union: an empirical analysis. Journal of Regulatory Economics 28(1), 4767.

Inderst, R., \& Peitz, M. (2012a). Network investment, access and competition. Telecommunications Policy 36, 407-418.

Inderst, R., \& Peitz, M. (2012b). Market asymmetries and investments in Next Generation Access Networks. Review of Network Economics 11, 1-27. Lipsky, A. \& Sidak, G. (1999). Essential Facilities, Stanford Law Review 51, 1187.

Newey, W. K. (1987). Efficient estimation of limited dependent variable models with endogenous explanatory variables. Journal of Econometrics 36, 231250.

Niskanen, W. A. (1971). Bureaucracy and Representative Government. Chicago: Aldine, Atherton.

Peltzman, S. (1976). Toward a more general theory of regulation. Journal of Law and Economics 19, 211-240.

Renda, A. (2016). Winners and Losers in the Global Race for Ultra-Fast Broadband: A cautionary tale from Europe. Report available at: http://www.macdonaldlaurier.ca/files/pdf/MLITelecomsPaper08-16webready-V2.pdf. 
Roodman, D. (2009). How to Do xtabond2: An Introduction to "Difference" and "System" GMM in Stata. Stata Journal 9(1), 86-136.

Sanderson, E. \& Windmeijer, F. (2016). A weak instrument F-test in linear IV models with multiple endogenous variables. Journal of Econometrics 190, 212-221.

Stigler, G. J. (1971). The theory of economic regulation. Bell Journal of Economics and Management Science 2, 3-21.

Vogelsang, I. (2013). The Endgame of Telecommunications Policy? A Survey. Review of Economics 64(3), 193-269.

Vogelsang, I. (2015). Will the U.S. and EU Telecommunications Policies Converge? A Survey. Economia e Politica Industriale (Journal of Industrial and Business Economics) 42(2), 117-155.

Vogelsang, I. (2017). The Role of Competition and Regulation in Stimulating Innovation - Telecommunications. Telecommunications Policy 41(9), 802812.

WIK (2012). NGA Progress Report. Report commissioned by ECTA. Bad Honnef. 